\title{
Antibacterial $\mathrm{Ag} / \mathrm{a}-\mathrm{C}$ nanocomposite coatings: The influence of nano-galvanic a-C and $\mathrm{Ag}$ couples on $\mathrm{Ag}$ ionization rates
}

\author{
N.K. Manninen ${ }^{\mathrm{a}, \mathrm{b}, *}$, S. Calderon V ${ }^{\mathrm{a}, \mathrm{b}}$, I. Carvalho ${ }^{\mathrm{b}, \mathrm{c}}$, M. Henriques $^{\mathrm{c}}$, A. Cavaleiro $^{\mathrm{a}}$, \\ S. Carvalho ${ }^{\mathrm{a}, \mathrm{b}}$ \\ a SEG-CEMUC, Mechanical Engineering Department, University of Coimbra, 3030-788 Coimbra, Portugal \\ b GRF-CFUM, Physics Department, University of Minho, Campus of Azurém, 4800-058 Guimarães, Portugal \\ ' CEB-Centre of Biological Engineering, LIBRO-Laboratório de Investigação em Biofilmes Rosário Oliveira, University of Minho, 4710-057 Braga, Portugal
}

\section{A R T I C L E I N F O}

\section{Article history:}

Received 1 February 2016

Received in revised form 9 March 2016

Accepted 14 March 2016

Available online 16 March 2016

\section{Keywords:}

Ag/a-C nanocomposites

Magnetron sputtering

Antibacterial

Nano-galvanic couples

Ag ionization

\begin{abstract}
A B S T R A C T
Biofilm formation has been pointed as a major concern in different industrial applications, namely on biomedical implants and surgical instruments, which has prompted the development of new strategies for production of efficient antimicrobial surfaces. In this work, nano-galvanic couples were created to enhance the antibacterial properties of silver, by embedding it into amorphous carbon (a-C) matrix. The developed $\mathrm{Ag} / \mathrm{a}-\mathrm{C}$ nanocomposite coatings, deposited by magnetron sputtering, revealed an outstanding antibacterial activity against Staphylococcus epidermidis, promoting a total reduction in biofilm formation with no bacteria counts in all dilution.

The open circuit potential (OCP) tests in $0.9 \% \mathrm{NaCl}$ confirmed that a-C shows a positive OCP value, in contrast to $\mathrm{Ag}$ coating, thus enhancing the ionization of biocidal $\mathrm{Ag}^{+}$due to the nano-galvanic couple activation. This result was confirmed by the inductively coupled plasma-optical emission spectroscopy (ICP-OES), which revealed a higher Ag ionization rate in the nanocomposite coating in comparison with the $\mathrm{Ag}$ coating. The surface of $\mathrm{Ag} / \mathrm{a}-\mathrm{C}$ and $\mathrm{Ag}$ coatings immersed in $0.9 \% \mathrm{NaCl}$ were monitored by scanning electron microscopy (SEM) over a period of $24 \mathrm{~h}$, being found that the $\mathrm{Ag}$ ionization determined by ICP-OES was accompanied by an $\mathrm{Ag}$ nanoparticles coalescence and agglomeration in $\mathrm{Ag} / \mathrm{a}-\mathrm{C}$ coating.
\end{abstract}

(c) 2016 Elsevier B.V. All rights reserved.

\section{Introduction}

The development of antibacterial surfaces has been pointed as an emerging strategy in different industrial applications, namely, in textiles, medical instruments, food packages and indwelling medical devices [1-3]. Most of living bacteria are found to grow in biofilms which strongly adhere to different types of surfaces, where they find a strategic survival mechanism. This phenomenon leads to the failure of different types of components used in the above mentioned applications, which represents a huge economic loss and also a public health concern when it comes to fields such as medical devices or food packages. Among different strategies adopted for the development of anti-infective surfaces, the incorporation or utilization of bulk materials, with intrinsic bactericidal activity has become a very current approach [2], where Ag-based materials have gained a great popularity. The use of $\mathrm{Ag}$ in bulk form has been

\footnotetext{
* Corresponding author at: SEG-CEMUC, Mechanical Engineering Department, University of Coimbra, 3030-788 Coimbra, Portugal.

E-mail address: nora.sousa@dem.uc.pt (N.K. Manninen).
}

ceasing over time and, presently, it is widely used in nanoparticle form, due to the enhanced antibacterial effect promoted by the higher surface to volume ratio.

Over the past decade great efforts have been dedicated to understand different aspects related to the antibacterial effect of $\mathrm{Ag}$ nanoparticles (NP), namely, their mechanisms of actuation and their stabilization in complex biological medium. The proposed mechanisms underlying the biocidal activity of $\mathrm{Ag}$ nanoparticles are: (i) release of $\mathrm{Ag}$ ions [4]; (ii) direct physical contact between bacteria and NP [5] and (iii) generation of free radicals [6]. This issue is still widely studied, and, presently, some controversial results are still being reported, with some authors claiming that the $\mathrm{Ag}$ antibacterial activity is related to the Ag ions action [7,8], while others claim that the other factors should also play a role $[9,10]$. Several fundamental studies regarding the ionization mechanisms of free Ag nanoparticles have been performed in mili-q water [11] and, more recently, in more complex biological medium simulating the real conditions found within the human body $[12,13]$. The results indicate that the $\mathrm{Ag}$ ionization is reduced in the presence of $\mathrm{Cl}^{-}$or $\mathrm{PO}_{4}{ }^{3-}$ ions, due to the formation of $\mathrm{Ag}$ complexes, and also in the presence of thiol and selenide containing compounds, which block 
the particle surface and prevent the dissolution [13], thus hampering the long term antibacterial activity, especially if considering that the Ag ions play a key role in $\mathrm{Ag}$ antibacterial efficiency.

The use of $\mathrm{Ag}$ nanoparticles in real applications comprises its incorporation in different matrix materials, including polymers/textiles [14,15] or bioactive glass [16], as well as in nanocoatings [17-27]. In the specific case of nanocomposite coatings their deposition can follow different routes, namely, physical vapor deposition methods, which allow to deposit multifunctional nanocomposite coatings, based on metal (Me) oxides $[19,20]$, nitrides [21,22], carbonitrides [23,24] or amorphous carbon [25-27] matrixes containing the $\mathrm{Ag}$ nanoparticles. In this context Ag-Ti coatings have also become very popular, own to their potential antibacterial activity and electrical properties, which are highly desirable for sensor applications $[28,29]$. These deposition methods allow to tailor the Ag nanoparticles size/amount and also the morphology of the matrix, being generally accepted that smaller particle sizes and more porous matrixes enhance the antibacterial activity; in fact, smaller NPs have higher reactivity and porous nanocoatings enhance the interaction with the electrolyte. Nevertheless, some issues are still not solved in what regards the Ag based nanocomposite coatings, namely: (i) the influence of the matrix chemistry on the antibacterial efficiency and (ii) the long term antibacterial activity. For instance, Kelly et al. [21] compared the behavior of different transition metal nitride coatings (TiN, ZrN and $\mathrm{CrN}$ ) alloyed with similar amounts of $\mathrm{Ag}$ and they found that, despite the very similar morphology of different nanocomposite coatings, the $\mathrm{CrN}$ showed the best antibacterial effectiveness, while for TiN matrix the antibacterial activity was not observed. The influence of the matrix of the coating on the antibacterial activity was not truly described in the paper, in particular the possible effect of its electrochemical activity.

The main goal of this research is to contribute for the understanding of the importance of the electrochemical properties of the matrixes for enhancing the Ag antibacterial effect of Ag-NPs containing nanocomposite coatings. In this work the in- vitro antibacterial activity of $\mathrm{Ag} / \mathrm{a}-\mathrm{C}$ nanocomposite coating is compared with $\mathrm{Ag}$ and a-C coatings and a special emphasis is given to the role of coatings electrochemical properties on $\mathrm{Ag}$ ionization and the evaluation of $\mathrm{Ag}$ nanoparticles evolution along the immersion time. The deposition method followed was dual magnetron sputtering, a well establish technique in industrial environment. Following this deposition method a specific type of diamond like carbon (DLC) coating can be obtained, which is generally classified as amorphous carbon (a-C), being characterized by a high amount of $\mathrm{sp}^{2}$ type bonds combined with $\mathrm{sp}^{3}$ bonds, which content is about 5\% [30].

\section{Material and methods}

\subsection{Coatings deposition}

a-C, $\mathrm{Ag} / \mathrm{a}-\mathrm{C}$ and $\mathrm{Ag}$ coatings were deposited by dc magnetron sputtering onto TEM grids with carbon foil (used for transmission electron microscopy (TEM) analysis) and stainless steel (SS316L), used for all the other characterization techniques. The deposition chamber contains two opposite magnetrons and a rotating substrate holder, being pumped by rotary (Pfeiffer Vacuum, DUO $20 \mathrm{M}$ ) and diffusion (BOC Edwards-Diffstak 160/700) pumps to a base pressure of $5 \times 10^{-4} \mathrm{~Pa}$. The a-C and $\mathrm{Ag}$ coatings were deposited using pure C (99.99\%) and $\mathrm{Ag}(99.99 \%)$ targets, respectively, while the $\mathrm{Ag} / \mathrm{a}-\mathrm{C}$ nanocomposite coating was deposited using both targets simultaneously. The targets have dimensions of $200 \mathrm{~mm} \times 100 \mathrm{~mm}$. Previously to deposition process the substrates were polished using emery paper (from 320 to 1200) and, afterwards, ultrasonically cleaned in acetone, ethanol and distilled water for $15 \mathrm{~min}$ in each solvent. In order to further improve the coatings adhesion to the substrate, an etching process was performed before each deposition in an argon atmosphere (Ar flow of $35 \mathrm{sccm}$ ) by applying a pulsed dc bias voltage of $575 \mathrm{~V}$ to the substrate holder, being the reverse time and frequency $1.6 \mu$ s and $250 \mathrm{kHz}$, respectively. Simultaneously, the $\mathrm{C}$ and $\mathrm{Ag}$ targets were connected to dc power supplies, and power densities of $1.75 \mathrm{~W} / \mathrm{cm}^{2}$ and $0.25 \mathrm{~W} / \mathrm{cm}^{2}$ were applied to the targets, respectively, in order to eliminate the contamination from their surface. During the etching process, the substrates were protected by a stainless steel shield. The depositions were performed with substrates rotating at $10 \mathrm{~cm}$ from the target with a constant speed of $18 \mathrm{rpm}$. A pulsed negative dc bias voltage of $50 \mathrm{~V}$ was applied to the substrate holder, and no additional heating was applied. During deposition, the Ar flow was kept at $42 \mathrm{sccm}$, which results in a deposition pressure of $5 \times 10^{-1} \mathrm{~Pa}$. The a-C and $\mathrm{Ag}$ coatings were deposited by applying power densities of $7 \mathrm{~W} / \mathrm{cm}^{2}$ and $0.09 \mathrm{~W} / \mathrm{cm}^{2}$ to the $C$ and $\mathrm{Ag}$ targets, respectively, whereas same power densities were used simultaneously for the deposition of $\mathrm{Ag} / \mathrm{a}-\mathrm{C}$ nanocomposite coating. The deposition times were adjusted in order to obtain a thickness of $1 \mu \mathrm{m}$ for a-C and Ag/a-C coatings and $300 \mathrm{~nm}$ for the $\mathrm{Ag}$ coating.

\subsection{Coatings chemical composition, structure and morphology}

The coatings chemical composition was determined by electron probe microanalysis (EPMA), in a Cameca SX 50 apparatus. Five punctual measurements were randomly performed on the sample surface, with an acceleration voltage of $10 \mathrm{kV}$. The coatingís structure was evaluated through grazing incidence X-ray diffraction (GIXRD) in a PANalytical X'Pert PRO MPD system using $\mathrm{Cu} \mathrm{K \alpha}$ radiation $(45 \mathrm{kV}$ and $40 \mathrm{~mA}$ ) with a parallel beam configuration. The incident beam optics consisted of a hybrid monochromator (with a $\mathrm{Cu}$ W/Si mirror and a double crystal Ge (220)). A parallel plate collimator $\left(0.7^{\circ}\right)$ and Soller slits $\left(0.004^{\circ}\right)$ were mounted on the path of the diffracted beam. A PIXcel detector in receiving slit mode was used for X-ray collection. The analysis were performed in grazing incidence mode with an angle of incidence of $1^{\circ}$. For the $\mathrm{Ag} / \mathrm{a}-\mathrm{C}$ coating an additional analysis was performed at an incidence angle of $0.1^{\circ}$, which is below the carbon critical angle ( $\alpha \mathrm{c}$, which is at about $0.2^{\circ}$ ), thus allowing to determine the grain size of $\mathrm{Ag}$ particles sitting on coatings surface. The $\mathrm{Ag}$ grain size was determined by Scherrer formula using the (111) peak [31]. The XRD peaks were fitted with pseudo- Voigt function, which allowed us to calculate either the full-width at half-maximum (FWHM) and the peak position ( $2 \theta$ ). The $\mathrm{Ag} / \mathrm{a}-\mathrm{C}$ coatingís morphology was evaluated through transmission electron microscopy analysis in a TEM Tecnai G2 apparatus working at $200 \mathrm{kV}$. The $\mathrm{Ag} / \mathrm{a}-\mathrm{C}$ coating observed in TEM analysis was deposited into TEM grid with carbon foils with a deposition time of $5 \mathrm{~min}$, which allowed to obtain a thickness of about $40 \mathrm{~nm}$, thus avoiding any need of sample preparation.

The coatings morphology in as-deposited state, after immersion in $0.9 \% \mathrm{NaCl}$ and after halo inhibition tests were monitored through scanning electron microscopy (SEM) in a SEM, EDAX Nova nanoSEM 200 equipment. The Ag particle size was determined by analyzing the SEM micrographs in ImageJ software; only particles with sizes above $10 \mathrm{~nm}$ and with circularity between 0.7 and 1 were considered.

\subsection{Silver ion release and electrochemical properties}

The open circuit potential (OCP) measurements were performed using a Gamry potentiostat REF600 in a classic three electrodes corrosion cell with platinum and saturated calomel (SCE) as counter and reference electrodes, respectively. The samples were immersed during $1800 \mathrm{~s}$ in a solution of $\mathrm{NaCl}$ concentrated at $0.9 \% \mathrm{w} / \mathrm{v}$ in equilibrium with air. The results of the electrochemical test were 
calculated as the average and standard deviations of at least three separate samples. All the potentials are expressed with respect to SCE electrode.

Silver ion release was analyzed using an inductively couple plasma optical emission spectrometer (ICP-OES) PERKIN ELMER OPTIMA 8000 . Samples with $20 \mathrm{~mm} \times 20 \mathrm{~mm}$ were immersed into a vessel containing $50 \mathrm{ml}$ of $0.9 \% \mathrm{NaCl}$ at room temperature. $2 \mathrm{ml}$ of the solution were taken out after $0,2,6,12$ and $24 \mathrm{~h}$ of immersion and reserved for ICP-OES in dark, to avoid precipitation. Two calibration curves were prepared using a silver standard solution for ICP (silver, plasma standard solution, specpure, Ag $1000 \mathrm{ppm}$ ), diluted in $\mathrm{HNO}_{3}$ at $5 \% \mathrm{v} / \mathrm{v}$ in order to mimic the standard solution matrix and $\mathrm{NaCl} 0.9 \% \mathrm{w} / \mathrm{v}$ to replicate the experimental conditions used for the samples. Both calibration curves showed indistinguishable results. At least 3 samples were evaluated and the standard deviation are presented. The results are expressed in ng of silver release in one $\mathrm{ml}$ of solution by $1 \mathrm{~cm}^{2}$ of sample $\left(\mathrm{ppb} \mathrm{cm}^{-2}\right)$.

It should be pointed out that the electrolyte used for OCP and $\mathrm{Ag}^{+}$release tests does not represent the one used in antibacterial tests, which would be the ideal approach; nevertheless, the tests were carried out using the same solution in order to perform a direct comparison between OCP and ICP results. In fact, the complex medium, such as the Tryptic Soy Broth (TSB) used for biological tests, turns the ICP-OES analysis complex, due to the presence of macromolecules such as proteins. Therefore, the results achieved in this solution cannot be directly correlated with the complex biological medium; nevertheless, from a thermodynamic point of view the first $\mathrm{Ag}$ salt formed in any biological solution is $\mathrm{AgCl}$, thus, the use of this electrolyte allows to draw some conclusions about the $\mathrm{Ag}$ ionization rate for comparison the behavior of $\mathrm{Ag}$ and $\mathrm{Ag} / \mathrm{a}-\mathrm{C}$ coatings.

\subsection{In vitro antibacterial activity}

\subsubsection{Agar diffusion test}

The antibacterial activity of a-C, $\mathrm{Ag} / \mathrm{a}-\mathrm{C}$ and $\mathrm{Ag}$ coatings were tested against Staphylococcus epidermidis (IE186 strain, a clinical isolate belonging to the CEB Biofilm Group collection). Zone of inhibition (ZoI) tests, adapted from Kirby-Bauer test [32], were carried out to determine the diffusion of silver from the coatings surface. The halo size was used as a qualitative measure of the sample activity. S. epidermidis was stored at $-80^{\circ} \mathrm{C}$ in Tryptic Soy Broth (TSB, Merck) containing $15 \%$ (vol/vol) glycerol. Cells were firstly grown for approximately $36 \mathrm{~h}$ in plates of Tryptic Soy Agar (TSA, Merck), and then a single colony was inoculated in TSB and incubated for $18 \mathrm{~h}$, at $37^{\circ} \mathrm{C}$ under a constant agitation of $120 \mathrm{rpm}$. Afterwards, the resultant cell suspension was adjusted to an optical density (OD) of 1.0 at $640 \mathrm{~nm}$ and properly diluted in TSB to $1 \times 10^{7} \mathrm{CFU} \mathrm{ml}{ }^{-1}$. The incubation of the bacteria in the agar was performed with the addition of $1 \mathrm{ml}$ of cells suspension to $14 \mathrm{ml}$ of cooled $\left(<50^{\circ} \mathrm{C}\right)$ TSA and placed into sterile plastic petri dishes. After medium solidification, the coated coupon (with dimension of $2 \mathrm{~mm} \times 2 \mathrm{~mm}$ ) (previously sterilized by exposure of $\pm 1 \mathrm{~h}$ to UV light) were placed separately on the top of an agar plate, with the coated side in contact with the agar, and incubated for $24 \mathrm{~h}$, at $37^{\circ} \mathrm{C}$. After the incubation period, the halo (zone of transparent medium, which means that there is no bacteria growth) formed around the sample was measured and photographed to record the results (images captured with Image $\mathrm{Lab}^{\mathrm{TM}}$ software). All experiments were repeated at least in three independent assays.

Scanning electron microscopy (SEM) was used to observe the coatings surface after halo test and three fields were used for image analysis.

\subsubsection{Biofilm formation}

In addition, bacterial colonization assays were performed. S. epidermidis was cultivated in a liquid medium, by inoculation of a single colony on $20 \mathrm{ml}$ of TSB and incubated for $18 \mathrm{~h}$ at $37^{\circ} \mathrm{C}$, and $120 \mathrm{rpm}$ (this procedure is the same above mentioned). Afterwards, the resultant cell suspension was adjusted to an optical density (OD) of 1.0 at $640 \mathrm{~nm}$ and properly diluted to a final concentration of approximately $1 \times 10^{5} \mathrm{CFU} \mathrm{ml}{ }^{-1}$ (this concentration is required in order to maintain the same order of magnitude as the agar diffusion test). Coated coupons, with dimensions $2 \mathrm{~mm} \times 2 \mathrm{~mm}$ (previously sterilized by exposure of $\pm 1 \mathrm{~h}$ to UV light) were inserted in sixwell plates and $3 \mathrm{ml}$ of cellular suspension was added to each well. The plates with the materials were then incubated at $37^{\circ} \mathrm{C}$ under $120 \mathrm{rpm}$ for $24 \mathrm{~h}$. After incubation of S. epidermidis strains, the coatings were gently washed with Phosphate Buffered Saline (PBS (1x)) to remove non-attached bacteria. Thereafter the adherent bacteria were detached from the coatings using an ultrasonic bath for 5-10 min. The bacteria were incubated with serial dilutions on TSA plates at $37^{\circ} \mathrm{C}$ for $24 \mathrm{~h}$, and then the number of Colony forming units (CFU) was counted. All assays were independently performed in at least three independent assays were performed.

Results from biological assays were compared using one-way analysis of variance by applying the Bonferroni multiple comparisons test, using the software GraphPad Prism. All tests were performed with a confidence level of $95 \%$.

\section{Results}

\subsection{Coatings structure and morphology}

Both a-C and Ag/a-C coatings show a similar thickness (of $1000 \mathrm{~nm}$ ). In order to achieve a similar thickness in both coatings the deposition time was decreased from $150 \mathrm{~min}$. (used for the deposition of a-C coating) down to $120 \mathrm{~min}$ for $\mathrm{Ag} / \mathrm{a}-\mathrm{C}$ coating deposition, which is due to the higher sputtering yield of $\mathrm{Ag}$ (3.12 for Ar bombardment at $500 \mathrm{eV})$ in relation to $\mathrm{C}(0.12$ for $\mathrm{Ar}$ bombardment at $500 \mathrm{eV}$ ) [33]. The chemical composition obtained by EPMA suggested that the a-C layer is composed only by carbon, as expected, while the $\mathrm{Ag} / \mathrm{a}-\mathrm{C}$ coating shows $20 \mathrm{at} . \% \mathrm{Ag}$; the level of oxygen originating from residual atmosphere and target contamination was relatively low (below 2 at.\% 0 ). Considering the density of $\mathrm{Ag}\left(10 \mathrm{~g} / \mathrm{cm}^{3}\right)$ and amorphous carbon $\left(2.2 \mathrm{~g} / \mathrm{cm}^{3}\right)$ [30], the $\mathrm{Ag} / \mathrm{a}-\mathrm{C}$ nanocomposite coating contains $30 \%$ of $\mathrm{Ag}$ in volume, indicating that the total thickness of $\mathrm{Ag}$ in this coating should be around $300 \mathrm{~nm}$. As a result, the Ag thin film, containing 100 at.\% of $\mathrm{Ag}$, was deposited with a thickness of $300 \mathrm{~nm}$ in order to get a similar volume and mass of $\mathrm{Ag}$ in relation to the $\mathrm{Ag} / \mathrm{a}-\mathrm{C}$ coating.

The coatings crystalline structure was evaluated by means of GIXRD analysis and the results are shown in Fig. 1, where the main fcc-Ag diffraction peaks are identified (ICDD 181730).

The diffraction pattern of Ag coating suggests that the only crystalline phase present in the coating is Ag. Regarding the $\mathrm{Ag} / \mathrm{a}-\mathrm{C}$ nanocomposite coating the only detectable crystalline phase is $\mathrm{Ag}$, which was somehow predictable since a-C coatings typically form amorphous phases [30]. In addition, $\mathrm{Ag}$ is a poor carbide former, thus silver tends to grow as a second phase in carbon coatings $[34,35]$. In order to get a better insight about the size distribution of Ag nanoparticles in the nanocomposite coating a GIXRD analysis was performed either below $\left(0.1^{\circ}\right)$ the carbon critical angle, which allows to evaluate the particle size in coating's surface, and above $\left(1^{\circ}\right)$ the carbon critical angle $\left(\alpha \mathrm{c}\right.$, which as at about $\left.0.2^{\circ}\right)$, which allows to determine the particle size in the coatingís bulk. The GIXRD difractograms of $\mathrm{Ag} / \mathrm{a}-\mathrm{C}$ nanocomposite coating are depicted in Fig. 1, together with the Ag coatingís diffraction pat- 


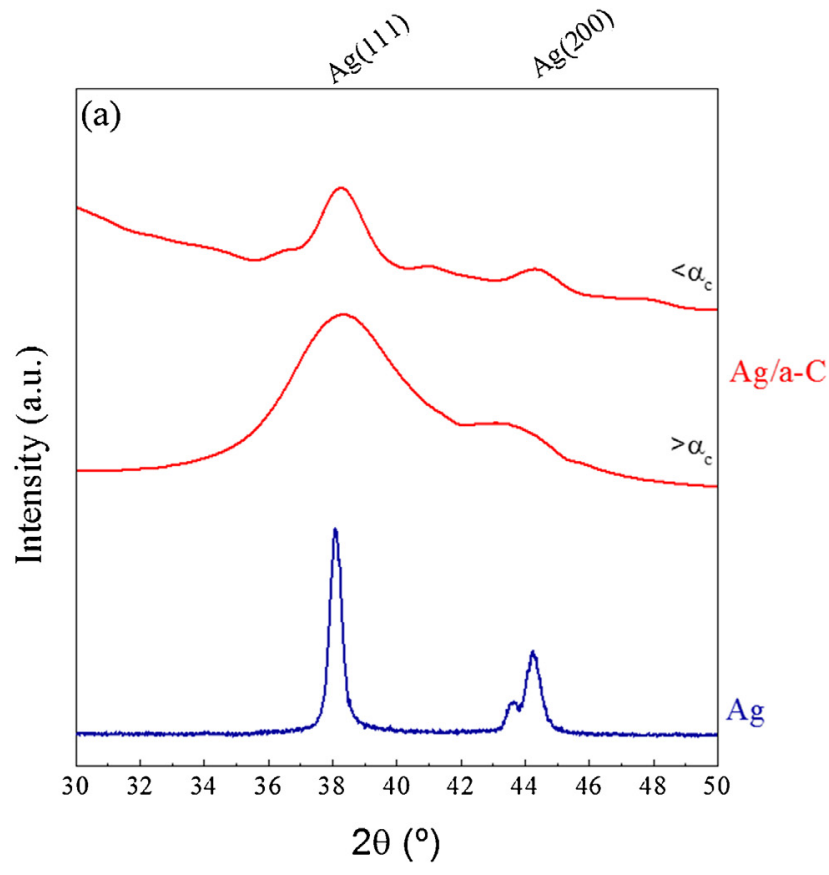

(b)

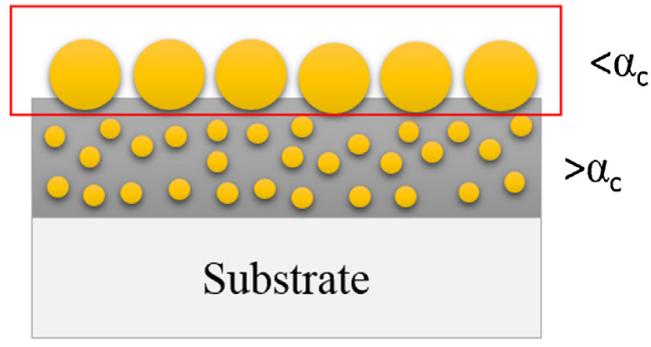

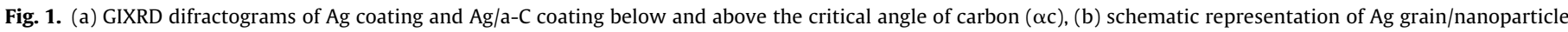
size distribution along the coatings depth.

tern. A schematic representation of the Ag grain/nanoparticle size distribution along the coatings thickness is also shown in Fig. 1(b).

The Ag grain size determined by Scherrer method [31] is about $47 \mathrm{~nm}$ in $\mathrm{Ag}$ coating. Regarding the $\mathrm{Ag} / \mathrm{a}-\mathrm{C}$ nanocomposite coating different trends can be found above and below the carbon critical angle $\left(\alpha \mathrm{c} \sim 0.2^{\circ}\right)$; the calculation of $\mathrm{Ag}$ grain size allowed to determine a value of about $20 \mathrm{~nm}$ below the $\alpha \mathrm{c}$ and $2 \mathrm{~nm}$ above $\alpha \mathrm{c}$. The results obtained in GIXRD analysis allowed to confirm the Ag grain size distribution along the coatingís thickness, which revealed that the coatingís surface is composed of bigger $\mathrm{Ag}$ grains with a size of about $20 \mathrm{~nm}$, while the Ag grains in the coatings bulk show smaller dimensions $(2 \mathrm{~nm}$ ). A schematic representation of the $\mathrm{Ag}$ particle size distribution along the coatingís thickness is shown in Fig. 1(b). A more detailed analysis and details about Ag particle size distribution following the GIXRD analysis is provided in [36].

TEM micrographs were recorded in order to get a better insight about $\mathrm{Ag}$ nanoparticles distribution in $\mathrm{Ag} / \mathrm{a}-\mathrm{C}$ nanocomposite coating.

The TEM image depicted in Fig. 2(a) suggests the presence of Ag nanoparticles with dimensions in order of 10-20 nm; a more detailed view (see Fig. 2(b)) shows a bimodal size distribution, with a high density of small Ag nanoparticles, with dimensions in the order of 2-3 nm, and bigger Ag nanoparticles with dimensions of about $20 \mathrm{~nm}$. These larger $\mathrm{Ag}$ nanoparticles should correspond to the ones detected at low incidence angles in GIXRD analysis, which should be sitting in coatings surface. These particles should be monocrystalline, since the grain size determined by GIXRD analysis is similar to the nanoparticle size found in TEM micrographs. The smaller particles are predominant in coatings bulk, according to the GIXRD analysis.

\subsection{Coatings electrochemical properties and Ag ionization rate}

The open circuit potential (OCP) of a-C and Ag coatings were determined and compared with the OCP value of $\mathrm{Ag} / \mathrm{a}-\mathrm{C}$ nanocomposite coating in $0.9 \% \mathrm{NaCl}$ electrolyte. The results are depicted in Fig. 3.
The OCP results clearly indicate that a-C coating shows the highest open circuit potential ( $0.14 \mathrm{~V} v s$. SCE), while Ag coating shows the lowest OCP value ( $-0.03 \mathrm{~V} v$ s. SCE). The $\mathrm{Ag} / \mathrm{a}-\mathrm{C}$ nanocomposite coating shows an intermediate behavior between $\mathrm{Ag}$ and $\mathrm{a}-\mathrm{C}$, with an OCP value around $-0.006 \mathrm{~V}$, which was somehow predictable taking into account the mixed potential theory which predicts that for two conductive phases in electrical contact the OCP should be located between the OCP values of its components [37], supporting the idea of galvanic couple between $\mathrm{nc}-\mathrm{Ag}$ and the a-C matrix to enhance the silver ion release.

The Ag ion release was monitored along time by means of ICPOES analysis, and the results are shown in Fig. 4.

The results suggest that both $\mathrm{a}-\mathrm{C}, \mathrm{Ag} / \mathrm{a}-\mathrm{C}$ and $\mathrm{Ag}$ coatings show dissimilar ionization rates along the immersion time studied $(24 \mathrm{~h})$. As expected, a-C coatings does not reveled any $\mathrm{Ag}$ ions over time due to its absence of silver. $\mathrm{Ag} / \mathrm{a}-\mathrm{C}$ coating, on the other hand, showed higher ionization rates in relation to $\mathrm{Ag}$ coating, being found that after $24 \mathrm{~h}$ the amount of $\mathrm{Ag}$ ions is about $35 \mathrm{ppb} \mathrm{cm}-2$ and $59 \mathrm{ppb} \mathrm{cm}^{-2}$, for solutions in contact with $\mathrm{Ag}$ and $\mathrm{Ag} / \mathrm{a}-\mathrm{C}$ coatings, respectively. The SEM micrographs of $\mathrm{Ag} / \mathrm{a}-\mathrm{C}$ and $\mathrm{Ag}$ coatings surface in as-deposited state, after $2 \mathrm{~h}$ and $24 \mathrm{~h}$ of immersion are shown in Fig. 5.

The SEM micrographs of $\mathrm{Ag} / \mathrm{a}-\mathrm{C}$ and Ag coatings in as-deposited state, shown in Fig. 5(a) and (d), respectively, suggest that the Ag/a$\mathrm{C}$ coating forms a nanocomposite coating, with $\mathrm{Ag}$ nanoparticles embedded in the a-C matrix, which is in good agreement with the GIXRD and TEM results. Conversely, the Ag coatingís micrograph suggests the presence of homogeneous coating typical from coatings composed by one single phase. The SEM micrographs of Ag/a-C coating shown in Fig. 5(b) and (c) (which represent the coatings immersed in $0.9 \% \mathrm{NaCl}$ for $2 \mathrm{~h}$ and $24 \mathrm{~h}$, respectively) clearly show that the Ag nanoparticles tend to agglomerate along time when immersed in $\mathrm{NaCl}$ solution, forming agglomerates with up to about $500 \mathrm{~nm}$ (see Fig. 5(b)), which are not visible in as-deposited state (see Fig. 5(a)).

The analysis of micrograph shown in Fig. 5(b) allowed to determine a mean particle size of about $60 \mathrm{~nm}$, being the smallest particle size about $25 \mathrm{~nm}$. In this analysis only particles with a circularity 

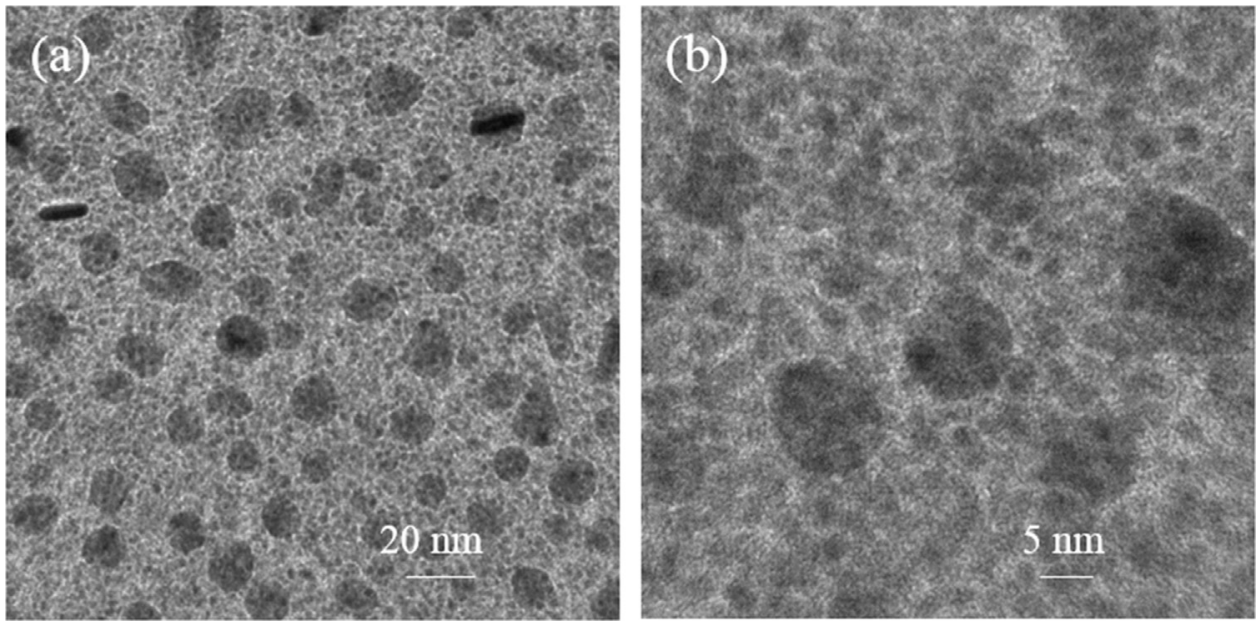

Fig. 2. TEM top-view micrograph of Ag/a-C coating recorded at a magnification of (a) $145 \mathrm{kX}$ and (b) $450 \mathrm{kX}$.

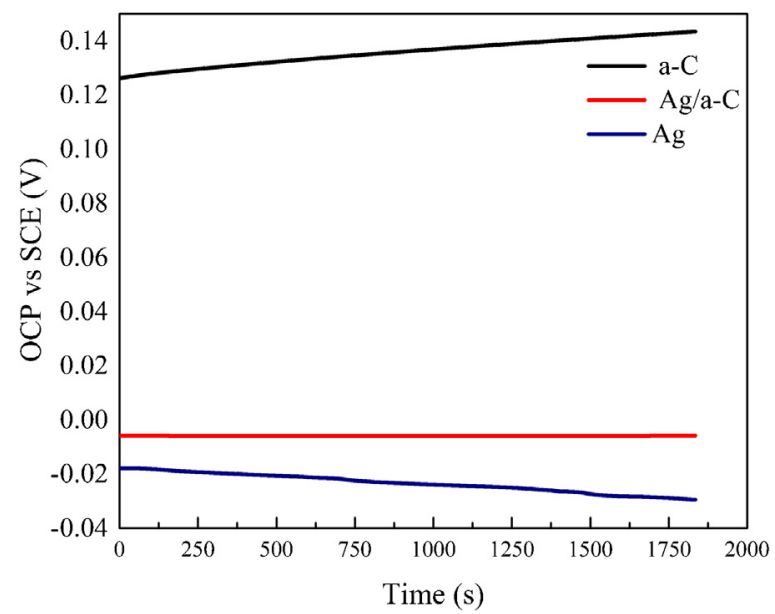

Fig. 3. OCP curves of a-C, $\mathrm{Ag} / \mathrm{a}-\mathrm{C}$ and $\mathrm{Ag}$ coatings.

between $0.7-1$ were considered, since the main aim is to determine the increase in the Ag particle size, without considering the Ag agglomerates. A similar analysis in the initial coating revealed a mean particle size of $25 \mathrm{~nm}$, a value much lower than the one observed in the coating immersed during $2 \mathrm{~h}$. After $24 \mathrm{~h}$ of immersion most of the particles are connected in agglomerates with several hundreds of nanometers, being the size of each individual nanoparticle clearly higher that in the initial stage, represented in Fig. 5(a). These particle agglomeration leads to a heterogeneous Ag particles coverage, as can be depicted in the inset of Fig. 5(c), where it is clear that the surface is composed of large areas with Ag agglomerates, combined with areas with no visible $\mathrm{Ag}$ particles. These observations suggest that possibly the particles are firstly increasing through a coalescence process, which should lead to formation of spherical particles, and thereafter this particles agglomerate. Over this period of time no visible changes are observed in Ag coating's surface.

\subsection{In-vitro antibacterial activity}

Fig. 6 shows an example of the halo tests carried out on different coatings and SEM images performed on the respective coating's surface after halo tests.

The Ag/a-C coating (Fig. 6(b)) shows a clear halo surrounding it, with a dimension of $\sim 2.4 \pm 0.02 \mathrm{~mm}$; the respective SEM image (see Fig. 6(e)) shows no bacteria on the coating surface, which is cov-

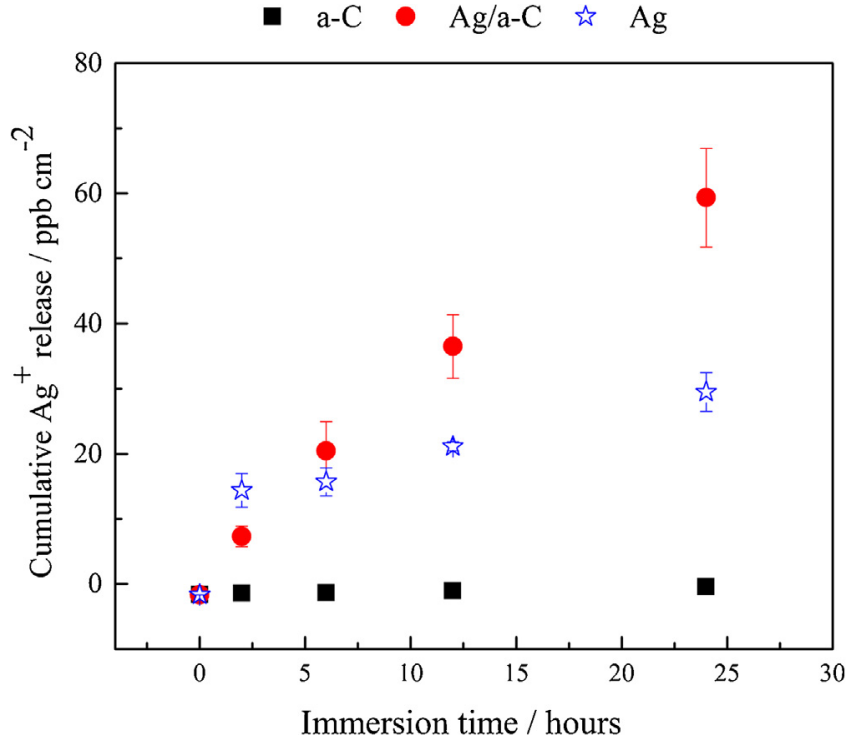

Fig. 4. $\mathrm{Ag}^{+}$release along time determined by ICP-OES analysis.

ered with Ag nanoparticles. Conversely, the a-C coating (Fig. 6(a)) does not show any halo around it and through observation of the respective SEM image (Fig. 6(d)) it is possible to observe microbial colonies on its surface. A similar behavior is observed in Ag coating. These results clearly demonstrate the lack of antibacterial activity in a-C and $\mathrm{Ag}$ coatings, while the $\mathrm{Ag} / \mathrm{a}-\mathrm{C}$ coating avoids the bacterial growth as confirmed by the existence of an inhibition zone and absence of bacteria on its surface.

To assess the number of viable cells, the cellular concentration was determined by CFU (Fig. 7) in terms of the logarithm of bacterial concentration (CFU ml-1 ${ }^{-1}$ ).

Fig. 7 shows that the addition of silver to a-C coatings promotes a total reduction in biofilm formation (this reduction is statistically significant $(P<0.0001)$ ), since no bacteria was found on the samples. These assays confirm the antibacterial activity of Ag/a$\mathrm{C}$ coating. Conversely, the $\mathrm{a}-\mathrm{C}$ and $\mathrm{Ag}$ coatings did not show any reduction in biofilm formation, thus suggesting the lack of antibacterial activity, in good agreement with the halo tests. 

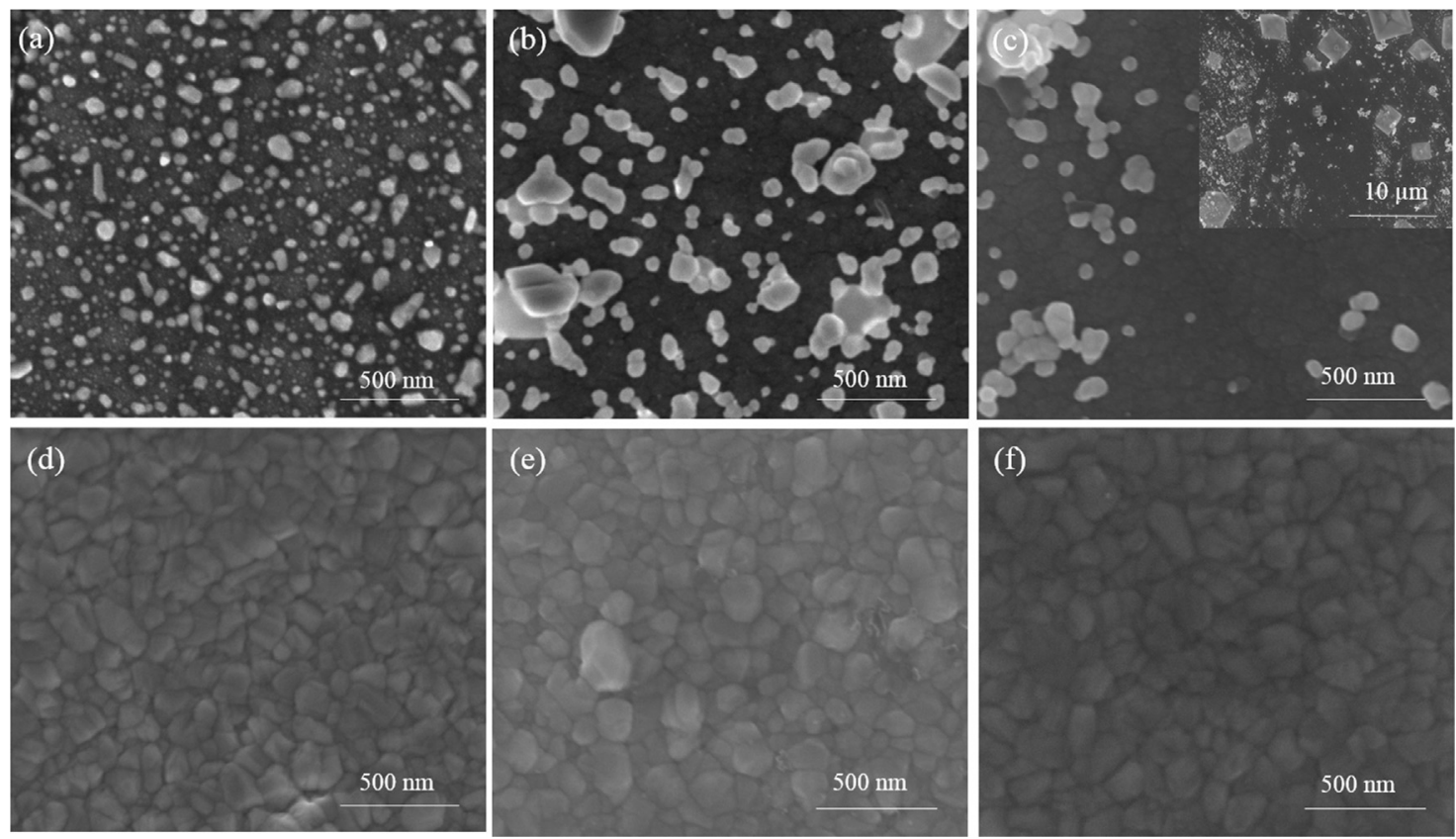

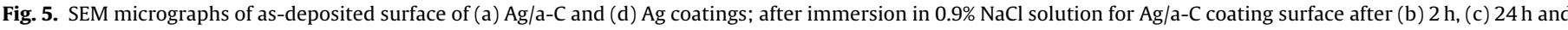
$\mathrm{Ag}$ coating after (e) $2 \mathrm{~h}$, (f) $24 \mathrm{~h}$.
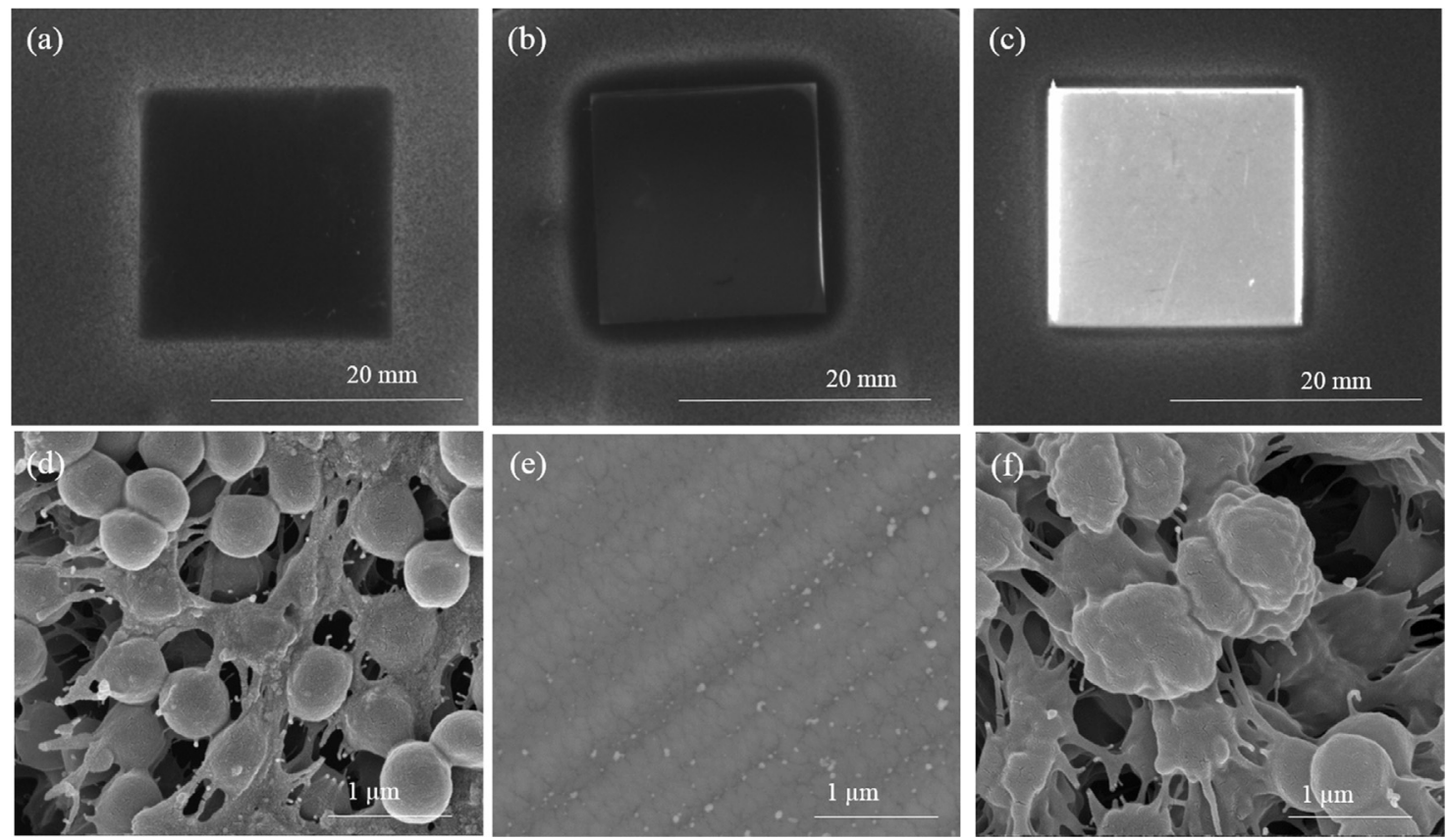

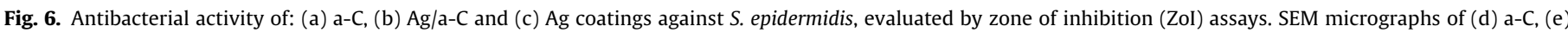
$\mathrm{Ag} / \mathrm{a}-\mathrm{C}$ and (f) Ag coatings surface, after Zol test.

\section{Discussion}

In this study $\mathrm{Ag} / \mathrm{a}-\mathrm{C}$ nanocomposite coatings were deposited by magnetron sputtering process and the antibacterial properties were compared with a-C and Ag coatings. The co-deposition of $\mathrm{Ag}$ and $\mathrm{C}$ results in the formation of nanocomposite coatings, where $\mathrm{Ag}$ nanoparticles are embedded in the a-C matrix coating, as suggested by GIXRD, TEM and SEM analyses. The growth of $\mathrm{Ag}$ as a second phase in the carbon matrix is mainly attributed to the low solubility of silver atoms in carbon [34,35]. These microscopy analyses combined with GIXRD results allowed to observe the bimodal
Ag NP size distribution along the coatings thickness, being found that the a-C matrix is composed by a large density of $2-3 \mathrm{~nm}$ sized Ag-NP, combined with a lower density of 20-25 nm sized Ag-NP, being the later ones siting in the coatings surface, while smaller $\mathrm{Ag}$ particles are embedded in the coating bulk. Similar trend has already been reported in magnetron sputtered $\mathrm{Ag}$ nanocomposite coatings in $\mathrm{TiO}_{2}$ matrix, being this bimodal size distribution attributed to the coalescence of surface Ag particles, promoted by the reduction in their free energy, a phenomenon not observed in the bulk, due to the restricted mobility of $\mathrm{Ag}$ atoms or nanoparticles inside the coating matrix [38]. This coating morphology permits the 


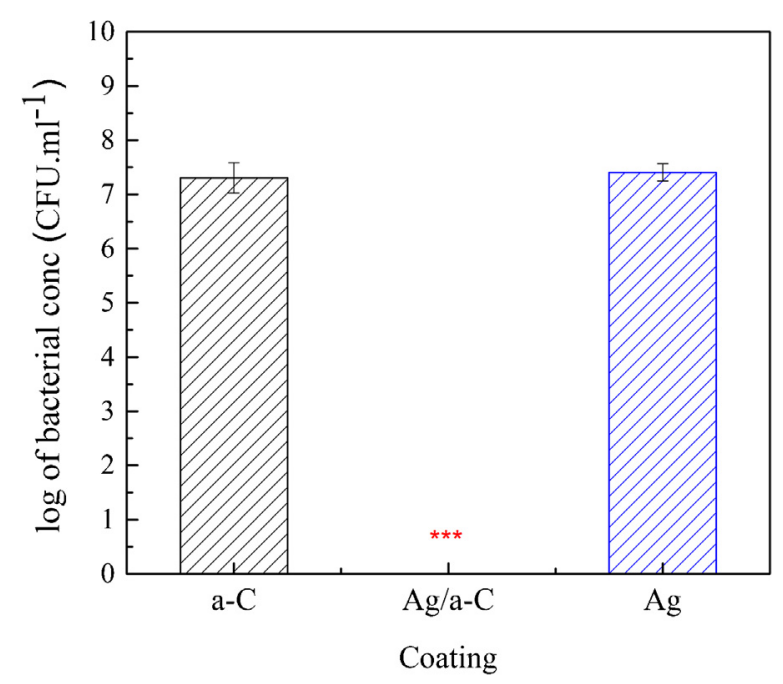

Fig. 7. Bacterial concentration logarithm after $24 \mathrm{~h}$ contact between S. epidermidis and sample. Asterisks $\left({ }^{* * * *}\right)$ denote statistically different from the control, (a-C is the control $)(\mathrm{P}<0.0001)$.

formation of two distinct electrical conductive phases, which allow the formation of a galvanic couple between the a-C and the silver nanoparticles, as confirmed by the OCP analysis (see Fig. 3). Such material configuration in contact with the electrolyte promotes a galvanic corrosion for the phase with lower reduction potential $(\mathrm{Ag})$. As a result, the a-C phase will act as cathode in the reaction and $\mathrm{Ag}$ as anode, thus enhancing the $\mathrm{Ag}$ ionization rate. On the contrary, for a pure silver coating, the silver ion release will be limited by the coatings crystalline structure, where the defects and grain boundaries promote the silver ionization. The driving force for the $\mathrm{Ag}$ ions release are the differences in the Gibbs free energy between the Ag grains and its grain boundaries, which tend to be more unstable, and thus more prone to be oxidized [18]. Nevertheless, due to the proximity between the OCP values expected in the silver in bulk and grain boundaries, the $\mathrm{Ag}$ ionization rate is lower in relation to a-C/Ag nanocomposite coatings. These two scenarios are schematized in Fig. 8.

In fact, the ICP-OES results over a period of $24 \mathrm{~h}$ (see Fig. 4) demonstrate that the $\mathrm{Ag}$ ionization rate in $\mathrm{Ag} / \mathrm{a}-\mathrm{C}$ nanocompos- ite coatings is higher in relation to the Ag coating, which was also ionized in this electrolyte.

During the $24 \mathrm{~h}$ of immersion, a linear increase in the $\mathrm{Ag}$ ionization rate is accompanied by an agglomeration of Ag surface particles, as observed in SEM analysis (see Fig. 5). During the first $2 \mathrm{~h}$ of immersion it is observed that the size of spherical particles increased from a mean value of $25 \mathrm{~nm}$ to $60 \mathrm{~nm}$, suggesting that some particle coalescence is occurring along with the formation of agglomerates, which amount increases over the next $24 \mathrm{~h}$. This suggests that in a first stage the particles are growing through a coalescence process, explained by the Oswald ripening process, which involves the dissolution of smaller Ag-NP with subsequent precipitation in bigger Ag particles surface [39]. However, the particles agglomeration indicates that not only a coalescence process occurs, but some silver mobility on the surface should arise in order that the agglomeration could take place. In liquid medium, free floating nanoparticles describe a Brownian motion that allows them to interact through weak van-der-Waals forces, thus resulting in particle agglomeration [39]. Nevertheless, the mechanism for this process still remains unclear since, assuming that the particles are immobilized in the coatings surface with distances around tens of nanometers, one would not expect any significant van-derWaals interactions, which only act at short distances. One possible hypothesis, might be the release of $\mathrm{Ag}$ nanoparticles to the liquid medium, due to the low affinity between the carbon phase and the metallic silver, followed by a posterior attachment to the coatings surface, which would allow them to easily agglomerate. However, the particles coalescence and agglomeration does not seem to reduce the Ag ionization rate, which increases linearly along the first $24 \mathrm{~h}$.

The antibacterial test revealed that the $\mathrm{Ag} / \mathrm{a}-\mathrm{C}$ coating shows antibacterial activity; conversely the a-C and Ag coatings do not inhibit the biofilm formation. These differences might be related with the different trends in Ag ionization, as confirmed by the ICPOES results. It should be pointed out that the antibacterial tests were performed over a period of $24 \mathrm{~h}$, and at the end of this time the amount of $\mathrm{Ag}$ ions in $\mathrm{Ag} / \mathrm{a}-\mathrm{C}$ coatings was about twice in relation to the amount of $\mathrm{Ag}^{+}$released from the $\mathrm{Ag}$ coating, which might be one reason for the enhanced antibacterial activity of nanocomposite coating. In fact, the biocidal activity of $\mathrm{Ag}^{+}$is well established being silver salts widely used as antibacterial agents. However, in what regards to the Ag nanoparticles other mechanisms are still under
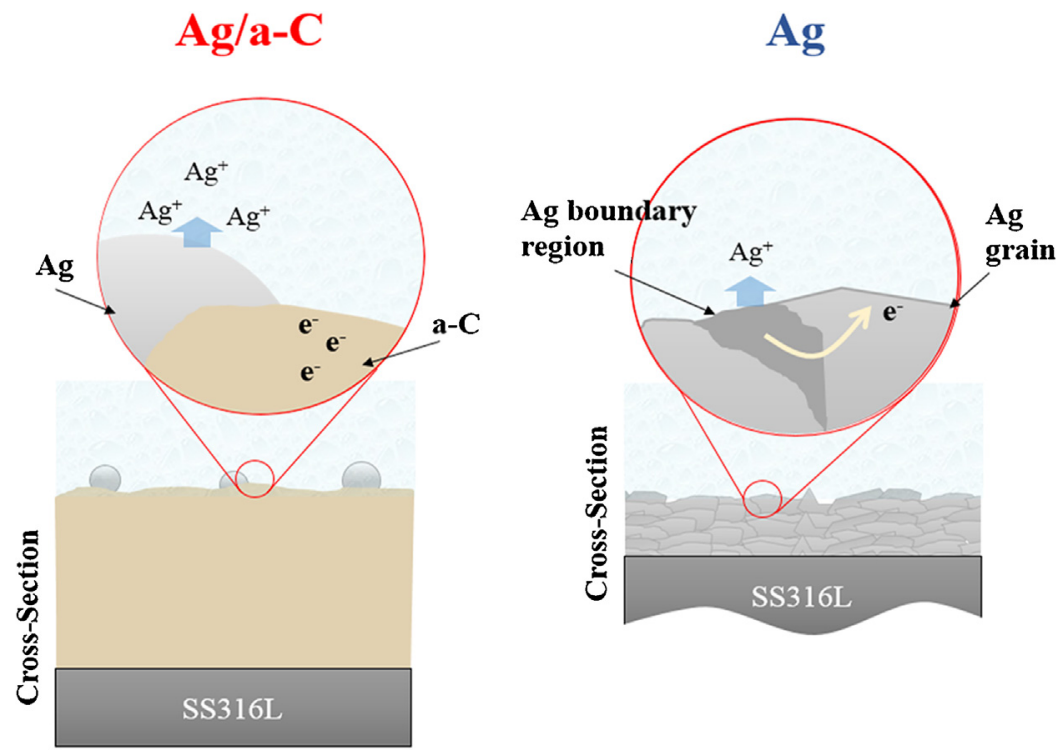

Fig. 8. Schematic representation of electrochemical reactions in $\mathrm{Ag} / \mathrm{a}-\mathrm{C}$ nanocomposite and $\mathrm{Ag}$ coatings. 
discussion, namely, the possible interaction of bacterial cells and Ag nanoparticles, being the later involved in damaging of bacterial cell wall and plasma membrane, or inhibition of DNA replication and protein synthesis [40-42]. As previously shown, the Ag coating is formed by a continuous Ag layer, while in the nanocomposite coatings the $\mathrm{Ag}$ is present in nanoparticle form with sizes between 3 and $25 \mathrm{~nm}$. These nanoparticles showed mobility on the surface, demonstrated by the agglomeration process and, thus, they might easily diffuse into the culture media, causing the killing of bacteria and, thus, contributing to an enhanced antibacterial activity.

\section{Conclusions}

$\mathrm{Ag} / \mathrm{a}-\mathrm{C}$ nanocomposite coatings were deposited by magnetron sputtering onto SS316L substrates and the electrochemical behavior, $\mathrm{Ag}$ ionization rate and antibacterial activity were compared with a-C and Ag coatings. The Ag and $\mathrm{C}$ co-deposition resulted in the formation of a nanocomposite coating, where $3 \mathrm{~nm}$ sized $\mathrm{Ag}$ nanocrystals were formed in the carbon-based matrix, while the surface was covered with $20 \mathrm{~nm}$ sized Ag nanocrystals.

The open circuit potential analysis revealed that the a-C coating shows a higher OCP value compared to $\mathrm{Ag}$, in $0.9 \% \mathrm{NaCl}$ electrolyte, thus meaning that the physical contact between $\mathrm{Ag}$ and a-C should result in an enhanced $\mathrm{Ag}$ ionization rate. The $\mathrm{Ag} / \mathrm{a}-\mathrm{C}$ nanocomposites form nano-galvanic couples, where $\mathrm{Ag}$ ionization rate is enhanced in relation to Ag coatings, as confirmed by the ICP-OES results. The $\mathrm{Ag}$ ionization in $\mathrm{Ag} / \mathrm{a}-\mathrm{C}$ coatings was accompanied by silver coalescence and agglomeration processes over the first $24 \mathrm{~h}$.

The antibacterial test indicated that both a-C and Ag coatings do not show any antibacterial effect against $S$. epidermidis biofilm formation, while the $\mathrm{Ag} / \mathrm{a}-\mathrm{C}$ coatings completely avoided the bacterial growth, which indicates an outstanding antibacterial efficiency. This antibacterial effect might be related with the higher Ag ions release in the nanocomposite coatings, as well as the presence of $\mathrm{Ag}$ nanoparticles, which might be enhancing the antibacterial effect.

\section{Acknowledgments}

This research is sponsored by FEDER funds through the program COMPETE-Programa Operacional Factores de Competitividade by national funds through FCT-Fundação para a Ciência e a Tecnologia-, in the framework of the Strategic Projects PESTC/FIS/UI607/2013, and PEst-C/EME/UI0285/2013, and with PhD fellowships SFRH/BD/82472/2011 and SFRH/BD/80947/2011.

\section{References}

[1] S. Chernousova, M. Epple, Silver as antibacterial agent: ion, nanoparticle, and metal, Angew. Chem. Int. Ed. 52 (2013) 1636-1653.

[2] D. Campoccia, L. Montanaro, C. Arciola, A review of the biomaterials technologies for infection-resistant surfaces, Biomaterials 34 (2013) $8533-8554$

[3] K. Vasilev, J. Cook, H. Griesser, Antibacterial surfaces for biomedical devices, Expert Rev. Med. Devices 6 (2009) 553-567.

[4] J.R. Morones, J.L. Elechiguerra, A. Camacho, K. Holt, J.B. Kouri, J.T. Ramirez, M.J. Yacaman, The bactericidal effect of silver nanoparticles, Nanotechnology 16 (2005) 2346-2353.

[5] I. Sondi, B. Salopek-Sondi, Silver nanoparticles as antimicrobial agent: a case study on E. coli as a model for Gram-negative bacteria, J. Colloid Interface Sci. 275 (2004) 177-182.

[6] J.S. Kim, E. Kuk, K.N. Yu, J.H. Kim, S.J. Park, H.J. Lee, S.H. Kim, Y.K. Park, Y.H. Park, C.Y. Hwang, Y.K. Kim, Y.S. Lee, D.H. Jeong, M.H. Cho, Antimicrobial effects of silver nanoparticles, Nanomed. Nanotechnol. Biol. Med. 3 (2007) 95-101.

[7] Z. Xiu, Q. Zhang, H.L. Puppala, V.L. Colvin, P.J.J. Alvarez, Negligible particle-Specific antibacterial activity of silver nanoparticles, Nano Lett. 12 (2012) 4271-4275.

[8] L. Sintubin, B.D. Gusseme, P. Van Meeren, B.F.G. Pycke, W. Verstraete, N. Boon, The antibacterial activity of biogenic silver and its mode of action, Appl. Microbiol. Biotechnol. 91 (2011) 153-162.
[9] G. Jin, H. Qin, H. Cao, Y. Qiao, Y. Zhao, X. Peng, et al., Zn/Ag micro-galvanic couples formed on titanium and osseointegration effects in the presence of S.aureus, Biomaterials 65 (2015) 22-31.

[10] M.A. Radzig, V.A. Nadtochenko, O.A. Koksharova, J. Kiwi, V.A. Lipasova, I.A Khmel, Antibacterial effects of silver nanoparticles on gram-negative bacteria: influence on the growth and biofilms formation mechanisms of action, Colloid Surf. B 102 (2013) 300-306.

[11] J. Liu, R.H. Hurt, Ion release kinetics and particle persistence in aqueous nano-Silver colloids, Environ. Sci. Technol. 44 (2010) 2169-2175.

[12] K. Loza, J. Diendorf, C. Sengstock, L. Ruiz-Gonzalez, J.M. Gonzalez-Calbet, M. Vallet-Regi, M. Koller, M. Epple, The dissolution and biological effects of silver nanoparticles in biological medium, J. Mater. Chem. B 2 (2014) 1634.

[13] J. Liu, D.A. Sonshine, S. Shervani, R.H. Hurt, Controlled release of biologically silver from nanosilver surfaces, ACS Nano 4 (11) (2010) 6903-6913.

[14] M. Yadollahia, H. Namazia, M. Aghazadeh, Antibacterial carboxymethyl cellulose/Ag nanocomposite hydrogels cross-linked with layered double hydroxides, Int. J. Biol. Macromol. 79 (2015) 269-277.

[15] G.M. Raghavendra, T.K. Jayaramudu, R. Varaprasad, S.S. Sadiku, K. Ray, Mohana Raju, Cellulose-polymer-Ag nanocomposite fibers for antibacterial fabrics/skin scaffolds, Carbohyd. Polym. 93 (2) (2013) 553-560.

[16] X. Chatzistavroua, J. Christopher Fenno, D. Faulk, S. Badylak, T. Kasugag, A.R. Boccaccinih, P. Papagerakis, Fabrication and characterization of bioactive and antibacterial composites for dental applications, Acta Biomater. 10 (8) (2014) 3723-3732.

[17] C.M. Tîlmaciu, M. Mathieu, J.P. Lavigne, K. Toupet, G. Guerrero, A. Ponche, J. Amalric, P.H. Noël, Mutin, In vitro and in vivo characterization of antibacterial activity and biocompatibility: a study on silver-containing phosphonate monolayers on titanium, Acta Biomater. 15 (2015) 266-277.

[18] S.B. Bant, K.S. Gill, R.E. Burrell, Nanostructure: dissolution and morphology characteristics of microcidal silver films deposited by magnetron sputtering, Acta Biomater. 3 (2007) 341-350.

[19] E. Unosson, D. Rodriguez, K. Welch, H. Engqvist, Reactive combinatorial synthesis and characterization of a gradient Ag-Ti oxide thin Film with antibacterial properties, Acta Biomater. 11 (2015) 503-510.

[20] P. Carvalho, P. Sampaio, S. Azevedo, C. Vaz, J.P. Espinós, V. Teixeira, J.O Carneiro, Influence of thickness and coatings morphology in the antimicrobial performance of zinc oxide coatings, Appl. Surf. Sci. 307 (2014) 548-557.

[21] P.J. Kelly, H. Li, P.S. Benson, K.A. Whitehead, J. Verran, R.D. Arnell, I. Iordanova, Comparison of the tribological and antimicrobial properties of $\mathrm{CrN} / \mathrm{Ag}$, ZrN/Ag, TiN/Ag, and TiN/Cu nanocomposite coatings, Surf. Coat. Technol. 05 (2010) 1606-1610

[22] S.M. Marques, I. Carvalho, M. Henriques, T. Polcar, S. Carvalho, PVD-grown antibacterial Ag-TiN films on piezoelectric PVDF substrates for sensor applications, Surf. Coat. Technol. 281 (2015) 117-124.

[23] I. Carvalho, M. Henriques, J.C. Oliveira, C.F. Almeida, A.P. Piedade, S. Carvalho, Influence of surface features on the adhesion of Staphylococcus epidermidis to Ag-TiCN thin films, Sci. Technol. Adv. Mater. 14 (2013) 035009.

[24] I. Ferreri, S.V. Calderon, R. Escobar Galindo, C. Palacio, M. Henriques, A.P. Piedade, S. Carvalho, Silver activation on thin films of Ag-ZrCN coatings for antimicrobial activity, Mater. Sci. Eng. C 55 (2015) 547-555.

[25] M.L. Morrison, R.A. Buchanan, P.K. Liaw, C.J. Berry, R.L. Brigmon, L. Riester, H. Abernathy, C. Jin, R.J. Narayan, Electrochemical and antimicrobial properties of diamond like carbon-metal composite films, Diamond Relat. Mater. 15 (2006) 138-146.

[26] K. Baba, R. Hatada, S. Flege, W. Ensinger, Y. Shibata, J. Nakashima, T. Sawase, T. Morimura, Preparation and antibacterial properties of Ag-containing diamond-like carbon films prepared by a combination of magnetron sputtering and plasma source ion implantation, Vacuum 89 (2013) 179-184.

[27] D. Bociaga, P. Komorowski, D. Batory, W. Szymanski, A. Olejnik, K. Jastrzebski, W. Jakubowski, Silver-doped nanocomposite carbon coatings (Ag-DLC) for biomedical applications-physiochemical and biological evaluation, Appl. Surf. Sci. 355 (2015) 388-397.

[28] S.M. Marques, N.K. Manninen, S. Ferdov, S. Lanceros-Mendez, S. Carvalho, Ti $1-x \mathrm{Ag}$ x electrodes deposited on polymer based sensors, Appl. Surf. Sci. 317 (2014) 490-495

[29] L. Bai, R. Hang, A. Gao, X. Zhang, X. Huang, Y. Wang, B. Tang, L. Zhao, P.K. Chu, Nanostructured titanium-silver coatings with good antibacterial activity and cytocompatibility fabricated by one-step magnetron sputtering, Appl. Surf. Sci. 355 (2015) 32-44.

[30] J. Robertson, Diamond-like amorphous carbon, Mater. Sci. Eng. R. 37 (2002) 129-281.

[31] P. Scherrer, N.G.W. Gottingen, Math. -Phys. Kl. 2 (1918) 96.

[32] Kirby-Bauer Disk Diffusion Susceptibility Test, American Society for Microbiology ASMMicrobeLibrary, 2016, Available online: Protocohttp:// www.microbelibrary.org/component/resource/laboratory-test/3189-kirbybauer-disk-diffusion-susceptibility-test-protocol.

[33] J.L. Vossen, J.J. Cuomo, Thin Film Processes, in: J.L. Vossen, W. Kern (Eds.), Academic Press, 1978, pp. 12-73.

[34] H. Woong Choi, J.-H. Choi, K.-R. Lee, J.-P. Ahn, K.H. Oh, Structure and mechanical properties of Ag-incorporated DLC films prepared by a hybrid ion beam deposition system, Thin Solid Films 516 (2007) 248-251.

[35] C. Wang, X. Yu, M. Hua, Microstructure and mechanical properties of Ag-containing diamond-like carbon films in mid-frequency dual-magnetron sputtering, Appl. Surf. Sci. 256 (2009) 1431-1435.

[36] N.K. Manninen, J.C. Oliveira, S. Carvalho, A. Cavaleiro, Characterization of surface Ag nanoparticles in nanocomposite a-C:Ag coatings by grazing 
incidence X-ray diffraction at sub-critical angles of incidence, Appl. Phys. A 122 (2016) 153.

[37] V.S. Calderon, A. Cavaleiro, S. Carvalho, Electrochemical response of $\mathrm{ZrCN}-\mathrm{Ag}-\mathrm{a}(\mathrm{C}, \mathrm{N})$ coatings in simulated body fluids, Electrochim. Acta 176 (2015) 898-906.

[38] V.S. Chakravadhanula, C. Kübel, T. Hrkac, V. Zaporojtchenko, T. Strunskus, F. Faupel, L. Kienle, Surface segregation in $\mathrm{TiO}_{2}$-based nanocomposite thin films, Nanotechnology 14 (49) (2012) 495701, 23.

[39] G. Cao, Nanostructures and Nanomaterials, Synthesis, Properties and Applications, Imperial College Press, U.S.A, 2004
[40] A. Taglietti, C.R. Arciola, A. D’Agostino, G. Dacarro, L. Montanaro, D. Campoccia, L. Cucca, M. Vercellino, A. Poggi, P. Pallavicini, L. Visai, Antibiofilm activity of a monolayer of silver nanoparticles anchored to an amino-silanized glass surface, Biomaterials 35 (2014) 1779-1788.

[41] L. Zhao, H. Wang, K. Huo, L. Cui, W. Zhang, H. Ni, Y. Zhang, Z. Wu, P.K. Chu, Antibacterial nano-structured titania coating incorporated with silver nanoparticles, Biomaterials 32 (2011) 5706-5716.

[42] K. Chaloupka, Y. Malam, A.M. Seifalian, Nanosilver as a new generation of nanoproduct in biomedical applications, Trends Biotechnol. 28 (2010) 580-588. 